\title{
Development of a Software for Design and Design Comparison of Prestressed I-Beam for Highway and Railway Bridges Based on International Standards
}

\author{
Mustafa Can Yücel \\ mustafacan@bridgewiz.com \\ Bridgewiz Engineering R\&D Co., Ankara, Turkey \\ Dilara Akdoğanbulut \\ dilara@bridgewiz.com \\ Bridgewiz Engineering R\&D Co., Ankara, Turkey \\ Alp Caner \\ acaner@metu.edu.tr \\ Middle East Technical University, Ankara, Turkey
}

\begin{abstract}
New computer software is being developed within Bridgewiz R\&D Co. for the aim of rapidly comparing design solutions for a prestressed I-beam (highway or railway bridge) according to different international specifications. The software will perform a series of beam designs based on user inputs and then make a comparison in terms of dimensions, material quantities, and total costs (using either user-defined or autoacquired unit prices). The design and comparison results will be presented to the user in the form of a PDF report (as well as an on-screen window) which includes tables and charts for easy visualization. The initial specifications that are planned to be included in the software are AASHTO-LRFD, EUROCODE, and Turkish Highway Bridge Specifications for highway bridges and AREMA, EUROCODE, and Turkish Railway Bridge Specifications for railway bridges. Fresh engineers will be able to use the program for verifying their designs and experienced engineers can utilize the program for staying up-to-date with requirements of contemporary specifications. The parameters that will be designed by the software are the optimum number of girders, their geometry, girder lateral spacing, number of prestressing tendons and jacking forces (taking the losses into account), prestressing tendon distribution, deck reinforcement area, and deck section stresses. The development is supported by KOSGEB - a Turkish government organization for supporting micro and small companies on research and development projects.
\end{abstract}

Keywords: Bridge; Design; Prestressed I-beam; Design comparison; Software

\section{INTRODUCTION}

Even though new technologies and construction techniques are continuously being developed for building bridges, most of the time these methods are used for bridges having an extraordinary feature such as long spans, increased heights, heavy loads...etc. For simpler and more common requirements, prestressed I-beam bridges are still widely preferred due to their standardized manufacturing process and ease of construction that result in lower costs and faster completion times. This trend can be seen in the ratio of I-beam bridges to the overall stock; the $97 \%$ of the bridges in Turkey and $75 \%$ of the bridges in the world are of I-beam (Figure 1). 

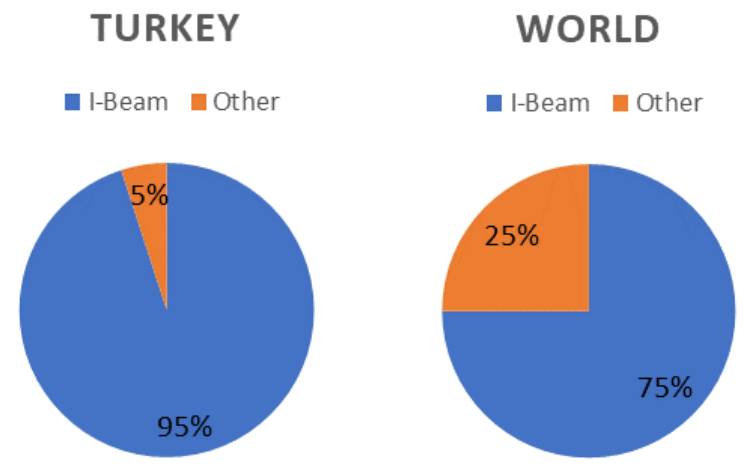

Figure 1: Quantity Distribution of Bridge Types in Turkey and the World

The common internationally-used specifications for these bridges are not beginnerfriendly and sometimes lead to confusion among inexperienced engineers. Moreover, if a foreign standard is used in a country (for example, AASHTO and EUROCODE are the most commonly used specifications in Turkey), the risk for miscalculations increases due to the language gap and the differences in engineering practices.

There are advanced software suites that can design a bridge according to the aforementioned specifications, however, most of the time these are sophisticated finite element programs that require extensive amounts of information, knowledge, and expertise on the subject as well as time-consuming model creation and analysis definitions. They are not optimized to be used for quick and simple partial designs, single item design verifications (such as the number of tendons needed) and education of fresh engineers on bridge design approaches. To close this lack of tools in the market, a new application that performs I-beam design according to the common specifications and compares the results is being developed. The application also aims to supply basic information on design practices for educational purposes, allowing fresh engineers to sharpen their skills in design practices. More experienced designers can also use the software to initiate a new design basis before proceeding to advanced computations. The software is developed using C\# language for Windows operating systems.

\section{SOFTWARE INPUT PARAMETERS, CALCULATION FLOW AND REPORTING}

For keeping the user experience non-complicated, the software is designed to ask the minimum number of necessary parameters from the engineer.

In the current development stage of the program, the following parameters are expected from the user to start a new design or design comparison:

1. Bridge type: The software is being developed to support two main bridge types according to their target vehicles: a highway bridge and a railway bridge. The selected type of bridge determines the available specifications that can be used in the design.

2. Specification: Based on the bridge type chosen in step 1, the available specifications 
are presented to the user. The currently available codes are given in Table 1. The selection of specification determines the live load vehicles (design trucks or trains) that will be available in the further steps, the design equations and the limits to be verified.

3. Unit system: To ensure the usability of the program in different regions, both the SI and Imperial unit systems are supported. Users may select either one of them, and it will change all the units within the app.

4. Span length: The total span that will be crossed by the I-girders. This parameter determines the geometrical properties of the girder cross-section as well as several prestressing properties.

5. Deck width: The total width of the deck. This parameter influences the total number of girders needed along the deck.

6. Girder type: The user is asked to select a starting girder type. There are several commonly used sections are predefined into the software, and a user-defined section option is added for custom I sections.

Table 1: Available Specifications for Bridge Types

\begin{tabular}{|c|c|}
\hline Highway Bridge & Railway Bridge \\
\hline AASHTO & AREMA \\
\hline EUROCODE & EUROCODE \\
\hline Turkish Bridge Design Guidelines & \\
\hline
\end{tabular}

Once these six parameters are defined, the user can continue with the design. In the next phase, the minimum and the maximum number of girders that can be used in the deck section are presented, and the user is asked the following parameters:

7. The number of girders: The user needs to select the number of girders, which has to be between the minimum and the maximum limits.

8. Slab thickness: The thickness of the slab.

9. Deck compressive strength: The concrete quality of the deck.

10. Strand properties: The physical properties of the pretensioning strands should be defined. This section includes diameter, spacing, and modulus of elasticity, ultimate strength, and minimum yield strength.

11. Enforce debonding limit: This option is to enable and disable the upper limit for the ratio of debonded strands to the overall number of strands.

Once these parameters are defined, the program can calculate the total number of strands, the number of debonded strands, and a preliminary strand distribution (Figure 2).

If the user wants to calculate an approximate cost of the total bridge, the following additional parameters are needed:

12. Pier information: The height and diameter of every pier.

13. Total bridge length: The total length of the bridge (not a single span length).

14. Unit price information: The software is shipped with default unit pricing for the 
construction materials, but these initial values should be revised based on regional market prices.

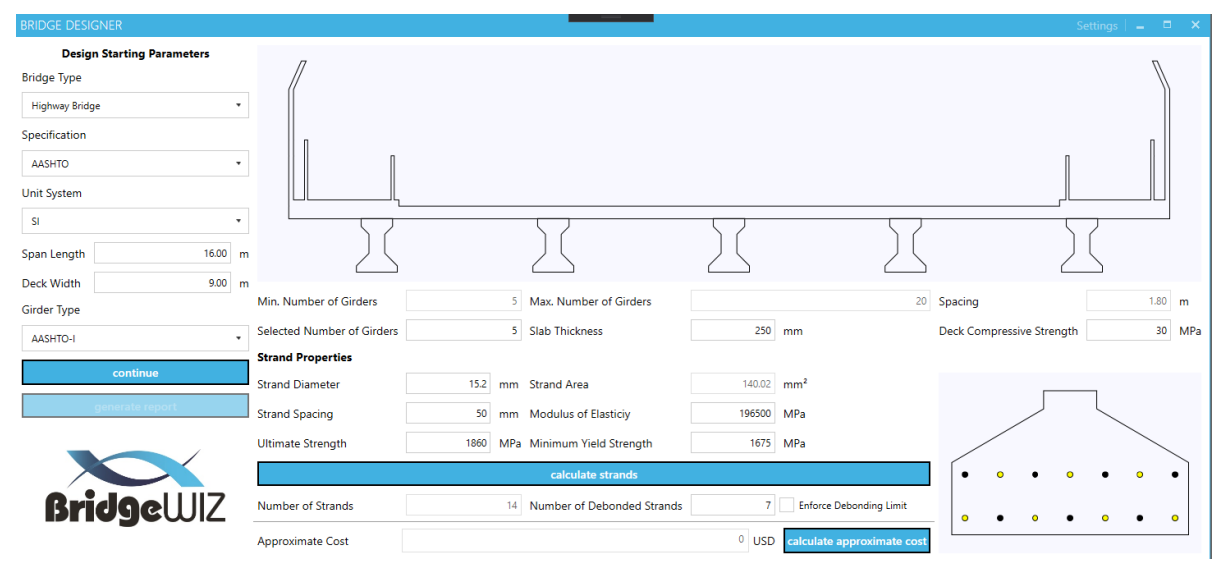

Figure 2: Strand Calculation Results

Once these additional parameters are entered, the software can calculate the approximated price for the bridge based on several assumptions, details of which are explained in further sections.

After performing the calculations, the user can get a PDF report which includes;

- Input parameters

- Section details

- Calculation details (such as dead and live load moments, prestressing forces after losses, single strand forces...etc.).

- Coarse cost estimation breakdown (concrete for superstructure and substructure, prestressing cable, reinforcement).

In the further development stages of the program, additional design calculations such as stress controls are planned to be implemented.

\section{CALCULATION DETAILS}

\subsection{Dead, Superimposed Dead and Live Loads}

The total moment generated by the dead load of the structure is assumed to be the maximum moment in a simply supported beam (1). The total dead load is calculated using the self-weight of girders and deck as well as weights of the sidewalk, wearing surfaces, barriers, and fences (superimposed).

$$
M_{d l}=w_{d l} L^{2} / 8
$$

The live load moment is determined considering the user-selected vehicle. The live load distribution on one girder is calculated according to the selected specification. For example, while using AASHTO, Article 4.6.2.2.2b is used (AASHTO, 2017). The impact factor is also determined according to the selected specification and the most critical effect of the live load is calculated (considering both the interior and the exterior girders). 


\subsection{Stress Limits for Concrete}

Stresses in concrete are checked at two phases; at the transfer of prestressing and at service condition with expected losses (2):

$$
\begin{aligned}
& f_{b c}=-\frac{P_{p}}{A_{g}}+\frac{P_{p} * e}{S_{t}}-\frac{M_{g d l}}{S_{t}}-\frac{M_{\text {slabw }}}{S_{t}}-\frac{M_{s d l}+M_{l l g}}{S_{t c}} \\
& f_{b t}=-\frac{P_{p}}{A_{g}}+\frac{P_{p} * e}{S_{b}}-\frac{M_{g d l}}{S_{b}}-\frac{M_{\text {slabw }}}{S_{b}}-\frac{M_{s d l}+M_{l l g}}{S_{b c}}
\end{aligned}
$$

The limiting values for the tensile and compressive stresses in concrete will be taken from the selected specification; for AASHTO Article 5.9.4.1 and 5.9.4.2 are used (AASHTO, 2017). Usually, girders cracked at construction stages are rejected to be used at the site and girders cracked at service times will decrease the economic life of the structure. Immediately after prestressing, the end zones of prestressed precast girder can crack due to excessive prestressing. At the service state, a section at mid-span can crack due to some overloading of the section. As known, cracking can reduce the economic life of the structure. Gravity loads developed over the time of construction and service typically results in downward deflection. Usually, compression develops at top fibers and tension develops at bottom fibers in the absence of prestressing. Prestressing reverses the gravity effects. Components of stresses induced by different load cases can be superimposed on to each other to determine cumulative stresses at the top and bottom fibers of the element at any section. At mid-span usually, top fibers are in compression and bottom fibers may or may not be in tension depending on the level of prestressing. Longitudinal cracks can develop due to excessive compression that can decrease the durability of the concrete. Therefore, it is better to limit the compression stresses to a limit. The prestressed precast girder design requires a crack-free design to maintain the durability of the element. The selected tensile stress limits are lower than a tensile strength of concrete that will not allow any cracking.

\subsection{Estimation of Minimum Required Number of Strands}

The quick assessment of the number of strands is based on a computation of tensile stresses induced by gravity loads that need to be balanced by prestressing. Prestressing will not only overcome tensile stresses but can deflect the girder upwards as it will happen at some stages of construction. Maximum tensile stresses develop at the service stage. The amount of prestressing steel needs to overcome these maximum tensile stresses. Combined gravity stresses and prestressing stresses at mid-span needs to be less than concrete stress limits. As expected, gravity loads will deflect the girder downward and prestressing effects will deflect it upwards. Gravity loads will develop compressive stresses at top fiber and tensile stresses at bottom fiber at the mid-span. These tensile stresses need to be balanced by the counteracting prestressing forces. The deck is made composite to the girder through extended ties of the girder that usually work as shear connectors. The effective width of the deck needs to be computed that will be part of the composite section. The specifications allow some tension at the bottom flanges 
of the section. Therefore, the tensile stresses that need to be balanced can be reduced by specification allowance. Total prestressing force can be computed from the tensile stresses that need to be balanced. The final stresses at the bottom will not reach the tensile stress limit of the specification. The number of strands that will develop the needed prestressing force can be computed based on the tensile stress limits of the strands. In the software, an approximate ratio of $20 \%$ losses is assumed for simplicity.

\subsection{Estimation of Approximate Cost}

The approximate cost of the bridge is calculated using the material quantity equations developed by statistical analyses (Hewson, 2003). In his study, Hewson proposed lower and upper limits for material quantities in terms of bridge type and deck area. In the software, only the upper limit is considered to prevent underestimation problems.

\section{ACCESSING THE SOFTWARE AND FUTURE PLANS}

The software is currently still under development and it is not open to closed or open testing yet. New specifications are being added and several new design checks will be added before any public release.

Any parties that are interested in the software can register their contact information to Bridgewiz to keep informed on any progress. The software is planned to be licensed per user for either limited or unlimited time.

\section{CONCLUSION}

A simple-to-use Windows PC software is being developed to establish preliminary design starting points or quick design checks/verifications as well as comparison of designs for different specifications. The software is targeted both to fresh engineers for preventing design errors and increasing their knowledge and senior engineers for quick calculations and getting up to date with new specification releases and code comparisons. The major aim of the software is to add a simple yet powerful tool to the engineer's arsenal for minimizing design starting errors and increasing efficiency of design processes. The software is still in development and will be available in near future to be sold using per-user licensing.

\section{REFERENCES}

American Association of State Highway and Transportation Officials (2017). AASHTO LRFD Bridge Construction Specifications, $4^{\text {th }}$ Edition.

Hewson, N. (2003). Prestressed Concrete Bridges: Design and Construction. ICE Publishing. 